\title{
Missing Omo L338y-6 Occipital- Marginal Sinus Drainage Pattern: Ground Sectioning, Computer Tomography Scanning, and the Original Fossil Fail to Show It
}

\author{
RALPH L. HOLLOWAY, ${ }^{1 *}$ MICHAEL S. YUAN, ${ }^{2}$ \\ DOUGLAS C. BROADFIELD,$^{3,4}$ DAVID DEGUSTA, ${ }^{5}$ GARY D. RICHARDS, ${ }^{6,7}$ \\ ADAM SILVERS, ${ }^{8}$ JILL S. SHAPIRO, ${ }^{1,9}$ AND TIM D. WHITE ${ }^{5}$ \\ ${ }^{1}$ Department of Anthropology, Columbia University, New York, New York \\ ${ }^{2}$ Department of Anatomy and Cell Biology, School of Dental and Oral Surgery, \\ Columbia University, New York, New York \\ ${ }^{3}$ Department of Anthropology, Florida Atlantic University, Boca Raton, Florida \\ ${ }^{4}$ Department of Cell Biology and Anatomy, Mount Sinai School of Medicine, \\ New York, New York \\ ${ }^{5}$ Department of Integrative Biology and Laboratory for Human Evolutionary Studies, \\ Museum of Vertebrate Zoology, University of California-Berkeley, \\ Berkeley, California \\ ${ }^{6}$ Laboratory for Human Evolutionary Studies, Museum of Vertebrate Zoology, \\ University of California-Berkeley, Berkeley, California \\ ${ }^{7}$ Department of Anatomy, University of the Pacific, School of Dentistry, \\ San Francisco, California \\ ${ }^{8}$ Department of Radiology, Mount Sinai Hospital, New York, New York \\ ${ }^{9}$ School of Continuing and Professional Studies, New York University, \\ New York, New York
}

\begin{abstract}
The Omo L338y-6 occipital region has been recently studied by White and Falk (1999), who claim that it shows a readily identifiable enlarged left occipital-marginal sinus (O/M). These observations are contrary to the direct observations of previous investigators (Rak and Howell, 1978; Kimbel, 1984; Holloway, 1981; Holloway, 1988). White and Falk (1999) further argue that the presence of this enlarged O/M strongly suggests that the Omo L338y-6 hominid was indeed a "robust" Australopithecus. We used direct sectioning and CT scanning to analyze magnified sections of a high-quality first-generation cast of the newly cleaned original fossil. These methods fail to show any evidence of a morphological landmark that can be interpreted as an enlarged O/M, either as an eminence or a sulcus. In contrast, the same techniques used with both SK 1585 and OH5 ("robust" Australopithecus with an enlarged O/M) show extremely visible and palpable enlarged O/M's. Examination of the original Omo fossil confirms that it lacks an O/M. This evidence clearly shows that an enlarged O/M cannot be identified on either the original fossil or a first-generation cast, although this does not rule out the possibility that the Omo L338y-6 hominid was a "robust" Australopithecus. We believe that the differences between observers regarding this feature are most probably due to displacement caused by a crack and the different source materials employed, i.e., the difference between a first-generation cast of the original fossil and a third- or fourth-generation cast of the endocast made two decades ago. Anat Rec 266:249-257, 2002. ๑ 2002 Wiley-Liss, Inc.
\end{abstract}

Key words: occipital-marginal sinus (O/M); drainage pattern; brain evolution; Australopithecus; brain endocasts; computer tomography; ground sectioning

In 1981, one of us (R.L.H.) published an endocranial volume determination and morphological observations on a Plio/Pleistocene hominid from the Omo Valley, Ethiopia, the Omo L338y-6 specimen (Holloway, 1981). The small size of the brain endocast $(427 \mathrm{ml})$, the lack of any detectable enlarged occipital-marginal sinus (O/M), and other details regarding the shape of the cerebellar lobes led R.L.H. to suggest that this specimen might not be a "ro-
*Correspondence to: Ralph L. Holloway, Department of Anthropology, Columbia University, New York, NY 10027. Fax: (212) 854-7347. E-mail: rlh2@columbia.edu

Received 25 July 2001; Accepted 14 January 2001 


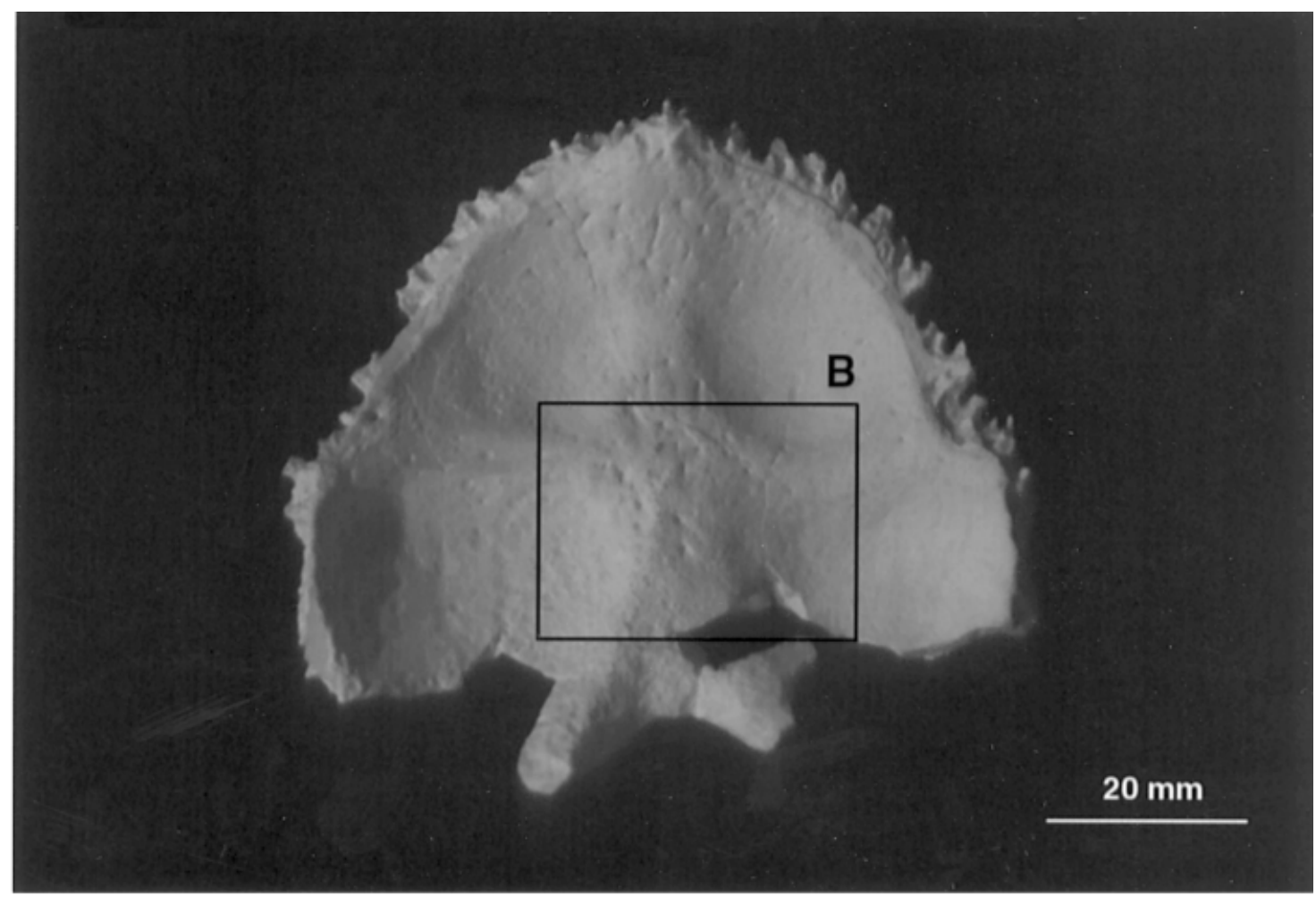

Fig. 1. A: Endocranial surface of the first-generation cast of the newly cleaned Omo L338y-6 occipital bone. The area of debate is outlined as a square and is enlarged in $\mathbf{B}$. There is no morphological evidence pointing to an enlarged left O/M. Note the obvious appearance of a crack line. 
bust" Australopithecus, as suggested by the discoverers in their early description (Rak and Howell, 1978).

Later, in a 1987 symposium dealing with the issue of "robust" australopithecines (Grine, 1988), R.L.H. indicated that he was no longer committed to his previous view, suggesting that the Omo L338y-6 specimen could have been either a gracile australopithecine or that of the taxon Australopithecus aethiopicus. The absence or presence of an enlarged $\mathrm{O} / \mathrm{M}$ was not an issue at that time.

More recently, White and Falk (1999), in addition to this literature, have claimed that the Omo L338y-6 shows an enlarged left $\mathrm{O} / \mathrm{M}$. They argue that given the presence of such morphology, the small size of the brain endocast, and certain size and shape parameters of the cerebellum, this specimen should be regarded as a clear-cut example of Australopithecus robustus (White and Falk, 1999). They claim that the enlarged left $\mathrm{O} / \mathrm{M}$ is readily visible and delineate its suggested presence by arrow markers in their Figure 2 illustration (White and Falk, 1999, p 403). As the enlarged $\mathrm{O} / \mathrm{M}$ has been consistently used by Falk and her colleagues (Falk and Conroy, 1983; Falk, 1986) to assign taxonomic status, and whereas it appears to be present on several different genera (e.g., Kimbel, 1984; Arsuaga et al., 1997; see also O'Loughlin, 1996), it is important that this feature be accurately identified. In line with R.L.H.'s earlier observations (Holloway, 1981, 1988), we believe that White and Falk's (1999) assessment of the anatomical presence of the enlarged $\mathrm{O} / \mathrm{M}$ is incorrect. Our goal in this paper is to test objectively the hypothesis that Omo L338y-6 has no identifiable enlarged $\mathrm{O} / \mathrm{M}$. We are not herein concerned with the ultimate taxonomic placement of this specimen, except secondarily.

\section{MATERIALS AND METHODS}

In order to evaluate the claim of a visible or palpable enlarged left O/M on the Omo L338y-6 occipital bone fragment or on the brain endocast, the following materials and procedures were prepared and followed in our investigations.

1. The original fossil specimen was carefully cleaned by G.D.R. under a dissecting microscope (magnification, $\times 40$ ). The molding was done by G.D.R. and the casts, among the first 10 from the mold, were made by T.D.W. using COECAL Dental Stone (GC Lab Technologies, Inc., Alsip, IL).

2. Serial sections of one cast were produced by G.D.R. by sanding the cast so as to produce sections at approximately 1 - to $2-\mathrm{mm}$ intervals perpendicular to the midsagittal plane and congruent with the endocranial-ectocranial plane. These sections were then scanned and digitized by D.D. at 600 dpi resolution using a flatbed scanner in gray-scale mode, commencing caudally from approximately the opisthionic portion of the foramen magnum portion and continuing superiorly to approximately the lambdoidal portion of the squamous part of the occipital. This same procedure was applied to casts of the occipital bones of OH5, an indisputably "robust" Australopithecus, which possesses a very distinct and clearly delineated enlarged O/M.

3. CT scans of the above specimens were also made by A.S., including the Australopithecus robustus, SK 1585, again at 1- to 2-mm intervals, horizontally across the casts of the occipital bone.

4. The original Omo L338y-6 fossil was studied by D.D. to

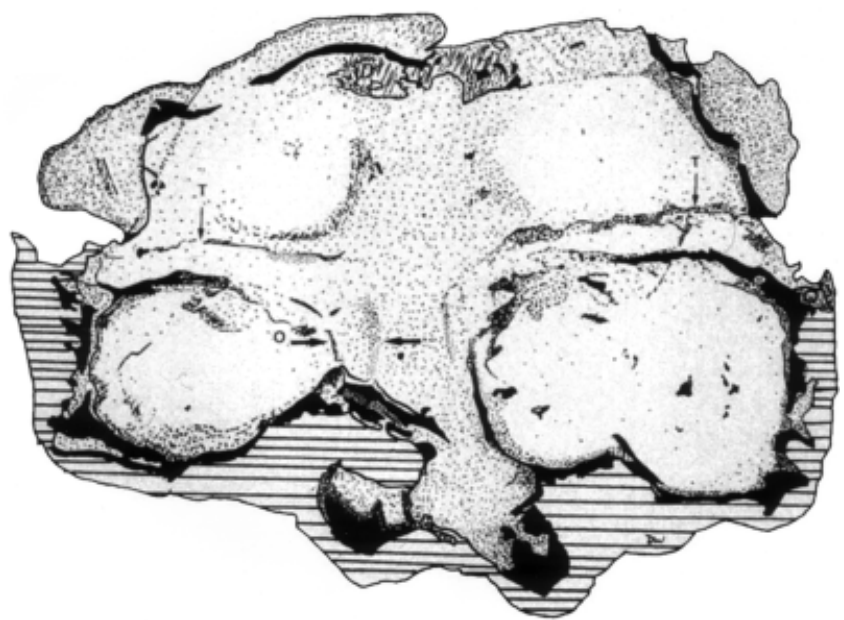

Fig. 2. From White and Falk (1999, p 403). This is the drawing of the Omo L338y-6 endocast used by White and Falk (1999) to depict by shading the area demarcated by two arrow points, which they interpreted as an enlarged O/M. No crack line appears in this version of the occipital endocranial morphology.

provide a complete comparison with what was described by White and Falk (1999). A dissecting microscope (magnification, ca. $\times 5-40$ ), controlled incident incandescent light, and careful palpation were used for the examination.

5. Using a dissecting microscope, polyvinylsiloxane (Coltène) peels of three partial Omo L338y-6 endocasts were examined at a magnification of roughly $\times 13$ to ascertain whether artifacts such as postmortem cracks could account for the purported enlarged O/M observation of White and Falk (1999). These partial endocasts of Omo L338y-6, limited to the areas of this research interest (the occipital and cerebellar regions), were molded from 1) the first-generation hydrostone occipital bone cast from T.D.W., 2) a cast from the collection of the Musée de l'Homme (Paris), and 3) the American Museum of Natural History (AMNH) cast. In addition, we examined the original AMNH endocast reconstructed by R.L.H. to provide a complete list of comparison to what was described and examined by D. White and Falk (1999).

The hypothesis to be tested is if an enlarged O/M exists on Omo L338y-6, there should be morphological features that would indicate either a visible and/or palpable elevation or depression created in the region by the $\mathrm{O} / \mathrm{M}$ that would also be similar, but not necessarily identical, to those found on the brain endocasts of OH5 and/or SK 1585 .

\section{RESULTS}

Figure 1 shows the endocranial surface of the firstgeneration Omo L338y-6 occipital bone cast with the area of debate magnified in the first-generation cast (G.D.R. mold). The sulci for the right and left transverse sinuses are clearly evident, demarcating the occipital and cerebellar lobes and leaving no further trace toward the area of the cruciform eminence. The width of the left transverse sinus is apparently larger than the right. There is no 

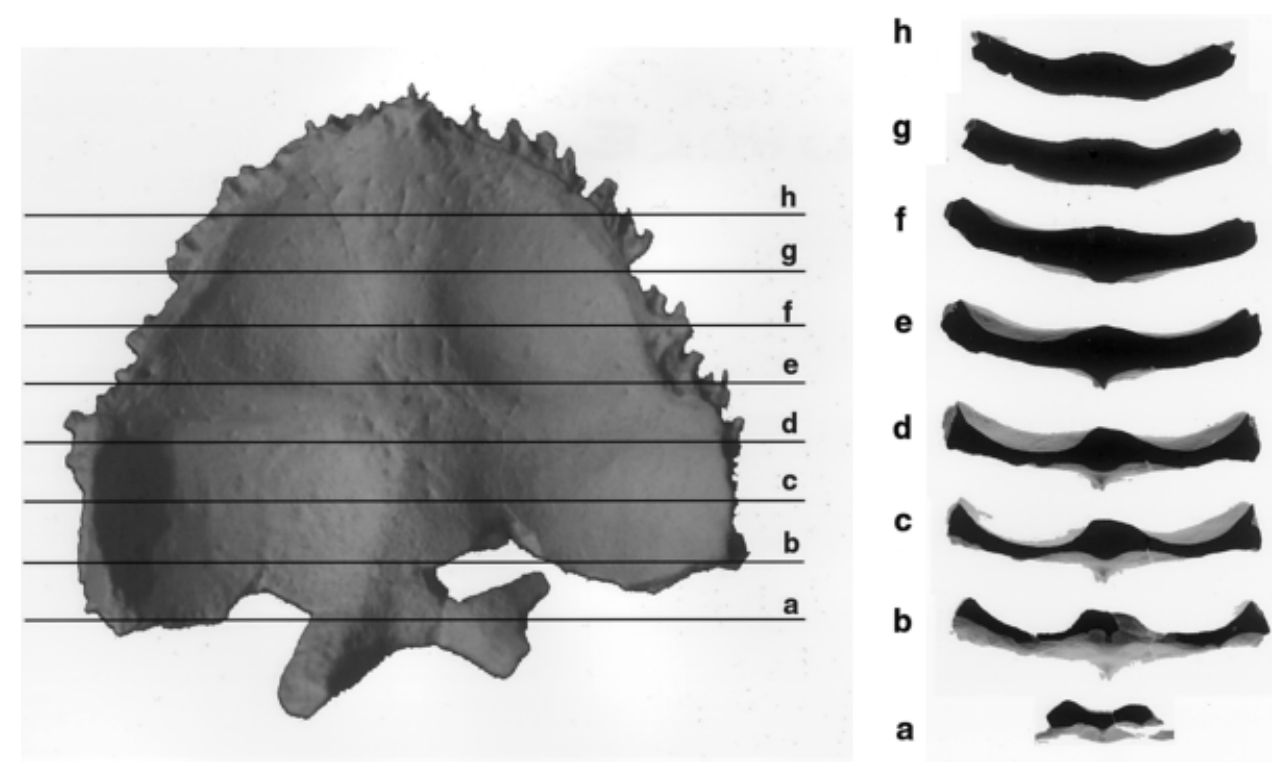

Fig. 3. A selection of 8 of the original 25 cross sections scanned to show the approximate locations in relation to the whole Omo L338y-6 occipital bone. The same method is applied to the preparation of $\mathrm{OH} 5$ cross sections in Figure 5.

morphological evidence pointing to an enlarged left O/M. Note that there is also a left vertical crack line extending from the broken border the left posterior cerebellar fossa, stretching upwards, bifurcating, and cutting along the left transverse sinus and the internal table of the occipital planum. The crack line, if not carefully observed, can easily be mistakenly regarded as the margin of a sinus.

Figure 2 shows the White and Falk illustration (1999, Fig. 2, p 403), depicting with arrows the purported enlarged O/M on Omo L338y-6. Note that there is no crack line, a point we will discuss later.

Figure 3 shows the relationship of the sectioning to the occipital morphology of the Omo L338y-6. It illustrates 8 of the 25 cross sections we obtained.

Figure 4 shows the six sections that cover the region of the occipital where White and Falk (1999) identify an enlarged O/M. It is clearly evident that no depressions or elevations are present in this region where White and Falk (1999) have indicated the presence of an enlarged $\mathrm{O} / \mathrm{M}$. In contrast, the enlarged right and left O/Ms are readily visible on the sections of the occipital bone cast of OH5 (Fig. 5), demonstrating that this method is fully capable of detecting enlarged $\mathrm{O} / \mathrm{Ms}$.

Figure 6 shows three computer tomographic sections relevant to White and Falk's (1999) supposed enlarged left $\mathrm{O} / \mathrm{M}$ area, as well as the relationship of the sectioning to the occipital morphology of the Omo L338y-6. Once again, we are unable to identify a depression or elevation in these sections. Figure 7 illustrates the enlarged right $\mathrm{O} / \mathrm{M}$ on the reconstructed $3 \mathrm{D}$ computer tomography of the SK 1585 endocast.

Since even the best casts are derivatives of the original, and thus have the potential for introducing artifacts, the original Omo L338y-6 fossil was studied by one of us (D.D.). Despite extensive manipulation of lighting and magnification and direct comparison with White and Falk's (1999) study, no trace of an O/M was identifiable or palpable on the original fossil.
These contrasts in morphology point to the obvious fact that the Omo L338y-6 occipital is totally devoid of an enlarged O/M. In sum, our investigations of directly sectioned casts, computer tomography-scanned casts, and the original fossil show conclusively that the hypothesis of an enlarged $\mathrm{O} / \mathrm{M}$ on Omo L338y-6 can be rejected: this specimen does not possess a visible or palpable enlarged $\mathrm{O} / \mathrm{M}$.

The cast of the Omo occipital bone made by T.D.W. from G.D.R.'s mold displays greater detail than is available on any of the other endocasts examined for this study, including those used by White and Falk (1999). White and Falk (1999) claimed that there is an enlarged left O/M along the medial border of the left cerebellar fossa. However, examination of this area in T.D.W.'s cast indicates that the lateral margin of White and Falk's (1999) O/M is not the edge of an enlarged $\mathrm{O} / \mathrm{M}$, but instead is the result of a vertical fissure created by the crack traversing the bone. This crack, along with its superior extension, is apparent in all the casts we examined (Fig. 8), as well as the original fossil. It is especially apparent and marked on the cast from the newly cleaned specimen (see Fig. 1). Moreover, it is obvious that the medial border of White and Falk's (1999) supposed O/M merely represents the medial border of the left cerebellar fossa and therefore the cerebellum.

\section{DISCUSSION}

Since the casts observed by White and Falk (1999) do not preserve the detailed anatomy available on the firstgeneration casts used in this study or in the original Holloway (1981) study, it is possible that they interpreted the presence of an enlarged $\mathrm{O} / \mathrm{M}$ based on specimens of lesser quality.

White and Falk (1999, p 400) provide the following description of their materials:

"Measurements were taken from a partial occipital endocast of Omo L338y-6 kindly provided by Alan 
Walker. The metric and morphological accuracy of our partial endocast was verified by comparing its measurements with those from a complete endocast of the Omo L338y-6 specimen (endocast A, reconstructed by Ralph Holloway) at the American Museum of Natural History (New York), and two casts of the Omo L338y-6 cranial bones housed at the Musée de l'Homme (Paris) and the American Museum of Natural History."

While we cannot speak directly to the generation of casts provided by Alan Walker or the Musée de l'Homme, we can speak of the casts at the AMNH. When R.L.H. (Holloway, 1981) finished his casting of the originals using latex rubber, the resulting positive endocast-a first-generation cast-was then cast using silicon rubber to produce a second-generation cast for later molding and duplication. A cast molded from this second-generation cast became the cast (third generation) upon which the full reconstruction was performed (Holloway, 1981). This third-generation cast was subsequently molded at the $\mathrm{AMNH}$, and casts from this mold (producing fourth-generation casts) would be the one(s) examined by White and Falk (1999). Repeated casting of a mold and subsequent generations of casts made of casts can potentially lose considerable detail from the original and introduce distortions and artifacts not present on the original (Clarke and Howell, 1972). This is very much like repeated photocopies of photocopied material, which often results in an increasingly corrupt image. Thus, the use of original fossils, or at least the critical evaluation of replica quality, is necessary (White, 2000). We believe that White and Falk's (1999) use of a fourth-generation cast contributes to our differences in observations regarding the enlarged O/M morphology.

As for the casts secured from Alan Walker (personal communication), he is not certain exactly where the copy used at the Kenya National Museums came from, i.e., whether from Dr. Clark Howell or from the Musée de l'Homme. If the former, the casts would be the dark brown plastic replicas, and any positive endocast from these would, necessarily, be at least either second- or thirdgeneration endocasts. Furthermore, such replicas derive from the first set of casts of the Omo hominids made using "Duzall plastic" or a similar material. These materials proved prone to distortion and often had a variety of artifacts (e.g., internal bubbles that artificially raise the surface) due in part to Duzall's extreme exothermic hardening reaction. Such artifacts can be hard to detect without comparison to the original fossil.

We believe the same applies to the Musée de l'Homme casts. Regardless of these important details, our study is based on the original fossil and first-generation casts of the newly cleaned original. The materials used by White and Falk (1999) are two to four generations removed from original material prior to its full cleaning.

Furthermore, we do not understand the logic behind White and Falk's (1999) insistence that should the Omo L338y-6 occipital fragment possess a distinct enlarged $\mathrm{O} / \mathrm{M}$, this specimen must be regarded as a "robust" Australopithecus. We believe that as this morphological landmark is variably present in different taxa, and even the same specimen (see below), considerable caution must be exercised in attempting to define these features. We note that Falk (1986) identified an enlarged $\mathrm{O} / \mathrm{M}$ in the Swanscombe occipital but could not find it on the Tautavel composite endocast. Actually, the occipital of the Tautavel

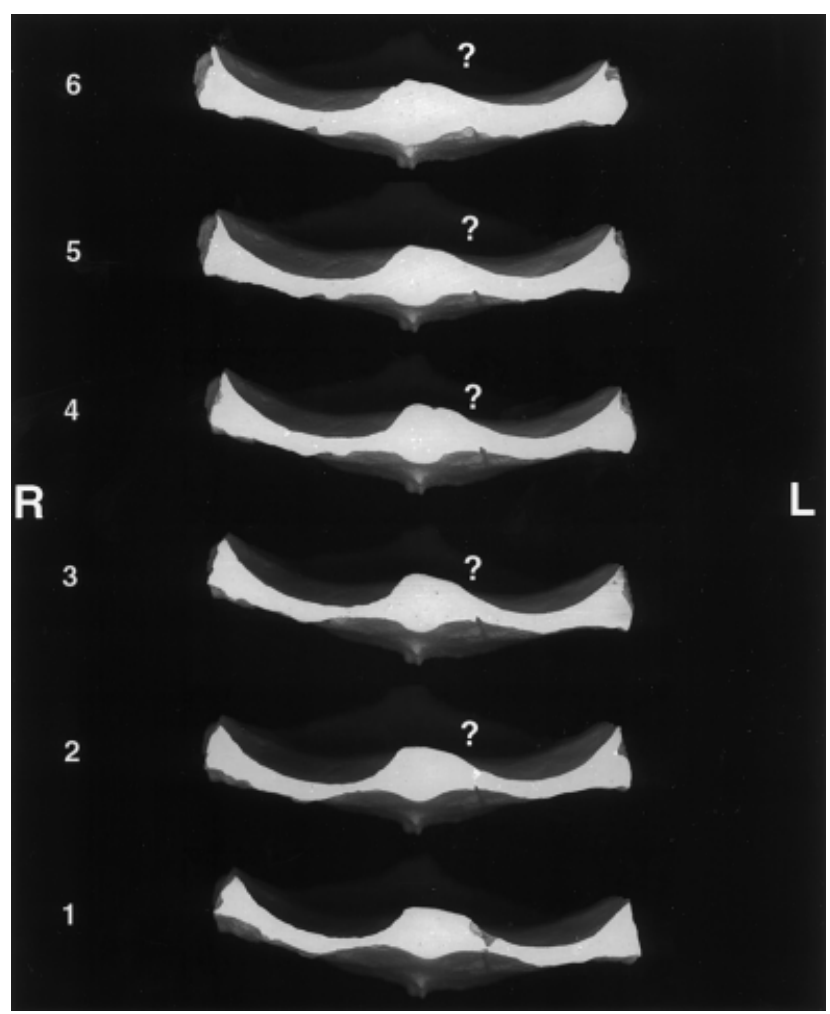

Fig. 4. These six sections, at approximately 1- to 2-mm intervals, cover the disputed region on the Omo L338y-6 occipital. The question marks indicate where there should be either an elevation or a depression representing the enlarged O/M, as indicated by White and Falk (1999). Neither elevations nor depressions are visible in these sections. Section 1 demonstrates the margin of the occipital broken region, which leads to a crack line, shown in section 2 . These sections should be compared to Figure 5.

composite was the Swanscombe occipital (see Arsuaga et al., 1997, p 269-270, for a description of this matter). We note that Falk (1986) and White and Falk (1999) are adamant that "robust" australopithecines all have one or more enlarged $\mathrm{O} / \mathrm{Ms}$, including the new Konso endocast (Suwa et al., 1997), which does not show such a feature (Holloway, manuscript in preparation). We also suspect that since the Omo L338y-6 endocast was smaller than any other "robust" Australopithecus, and since Falk et al. (2000) have recently claimed that all other "robust" Australopithecus endocast volumes have been inflated, the presence of an enlarged O/M on Omo L338y-6 would buttress their argument for its taxonomic assignment to Australopithecus robustus. Our findings do not solve that issue, but merely indicate that the Omo L338y-6 specimen does not have a clearly delineated enlarged O/M.

In addition, we note the clear presence of a crack line (see Figs. 1 and 8) running inferio-superiorally on the supposedly lateral margin of White and Falk's (1999) enlarged left $\mathrm{O} / \mathrm{M}$, as indicated on their illustration. We are puzzled as to why none of the casts described by White and Falk (1999) show any crack line, which was present on the original specimen and those described after the most recent cleaning. Since White and Falk (1999) do not describe or illustrate such a crack, we are compelled to question the 


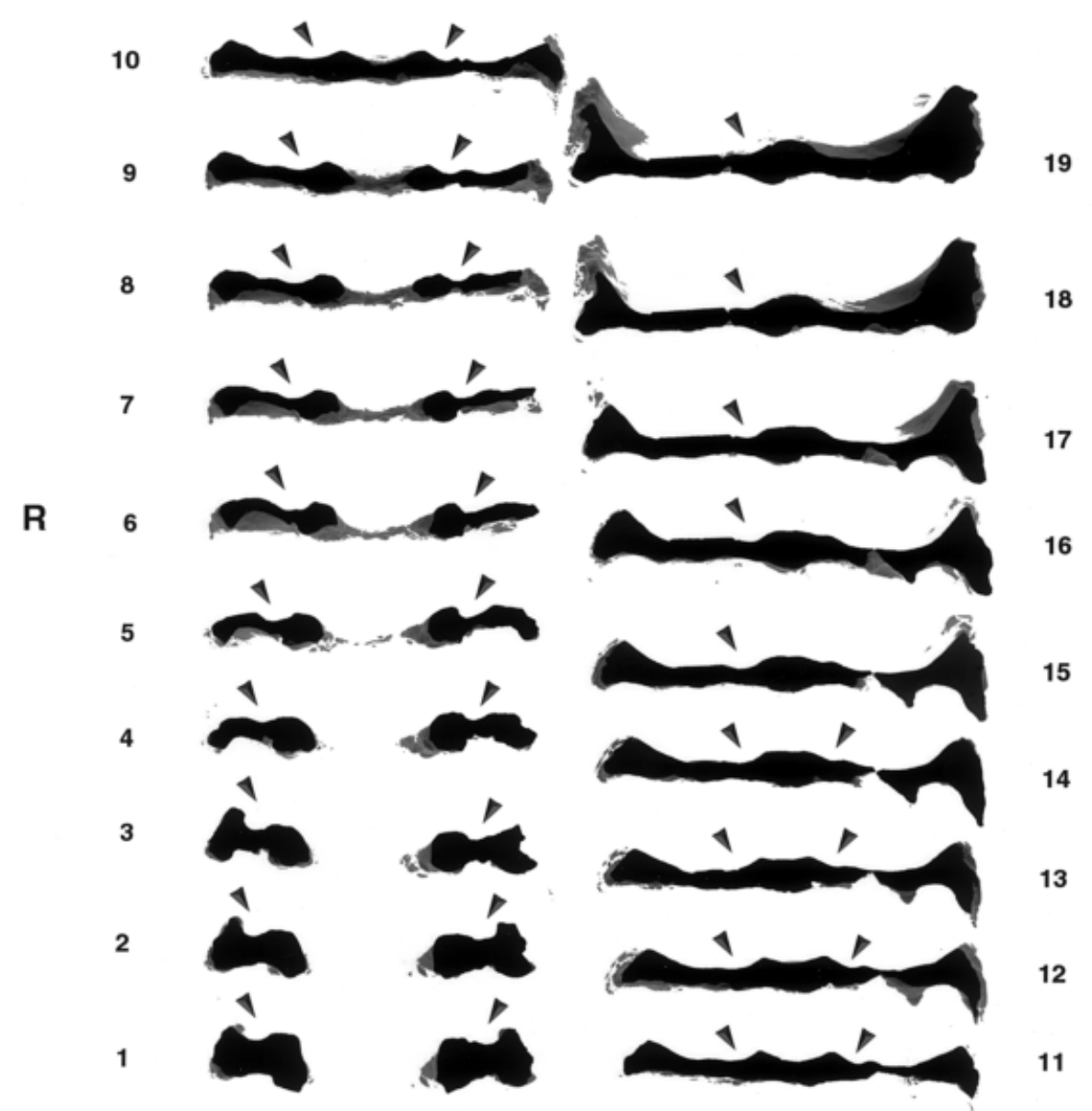

Fig. 5. This shows 19 sections through the occipital portion of $\mathrm{OH}$ 5, a known Australopithecus boisei, with very distinct enlarged bilateral O/M (arrows) from the inferior section 1, which cuts across foramen magnum, to the superior section 19. Compare with Figure 4.

quality of their cast and therefore any conclusion derived from such casts.

Rak and Howell (1978) did not observe an enlarged O/M on the original specimen. R.L.H. (Holloway, 1981) did not observe one from his first-generation cast, nor did Kimbel (1984). As Kimbel (1984) demonstrated, this morphological pattern can be seen in many primate taxa, i.e., Pan, Gorilla, Australopithecus, and Homo, but he did not find one on this specimen. O'Loughlin (1996) specifically warns that this feature is extremely variable. Most recently, Broadfield et al. (2001) have described this feature on the new Poloyo (Sm3) brain endocast from Homo in Indonesia. Despite the near universal appearance on the brain endocasts of "robust" Australopithecus, one would expect the enlarged $\mathrm{O} / \mathrm{M}$ to be a variably penetrant, absent or present nonparametric occurrence. The absence of an enlarged $\mathrm{O} / \mathrm{M}$ on the Omo L338y- 6 brain endocast cannot be used to declare the Omo L338y-6 as either "robust" Australopithecus or not. Moreover, we do not believe this feature can, by itself, be used to assign a fossil specimen to a taxon.

We remain skeptical of the taxonomic assessment of Omo L338y-6 as a "robust" Australopithecus and suggest that it will be the remaining morphological patterns that will decide that issue. As said earlier in Holloway (1988, p 98-99):

"Finally, the KNM-WT 17000 endocast bears a strong resemblance to the Omo L338y-6 specimen described previously ... In that description, it was concluded that Omo L338y-6 need not be a "robust" australopithecine as ... declared by Rak and Howell (1978). That specimen also lacks an O/M drainage pattern and shares a low cerebral-to-cerebellum height with the KNM-WT 17000 specimen, as well as a low cranial capacity (e.g., $427 \mathrm{ml}$ ). I tend to believe that KNM-WT 17000 is ancestral to A. boisei and A. robustus and that while the Omo L338y-6 specimen is perhaps indeed a "robust" australopithecine, it is uncertain that Omo L338y-6 represents A. boisei."

\section{CONCLUSIONS}

1. Neither direct horizontal sectioning nor computer tomography scanning at horizontal intervals of 1-2 $\mathrm{mm}$ on a first-generation cast shows any evidence for either a depressed or elevated enlarged left $\mathrm{O} / \mathrm{M}$ on the newly 


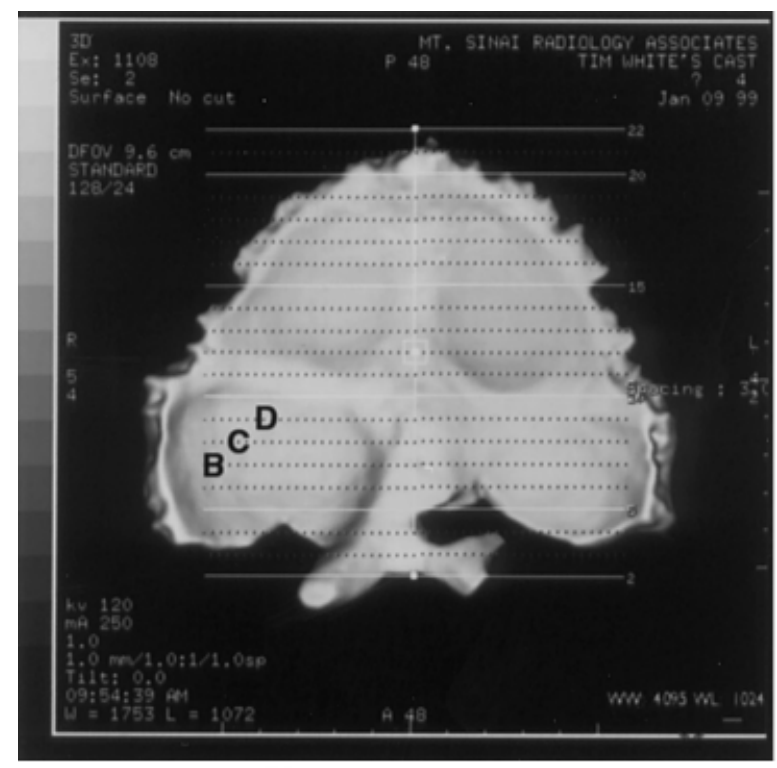

A

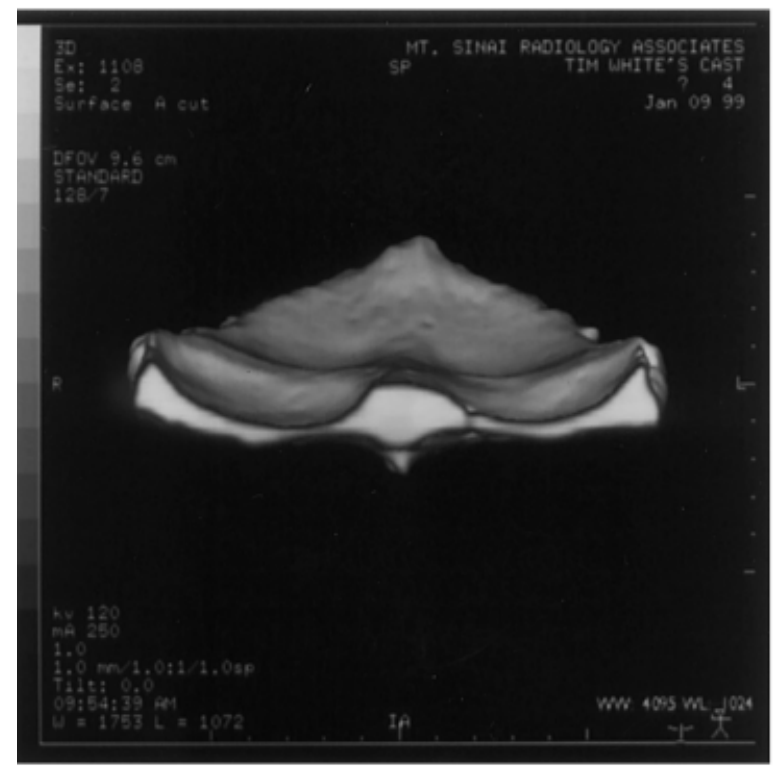

B

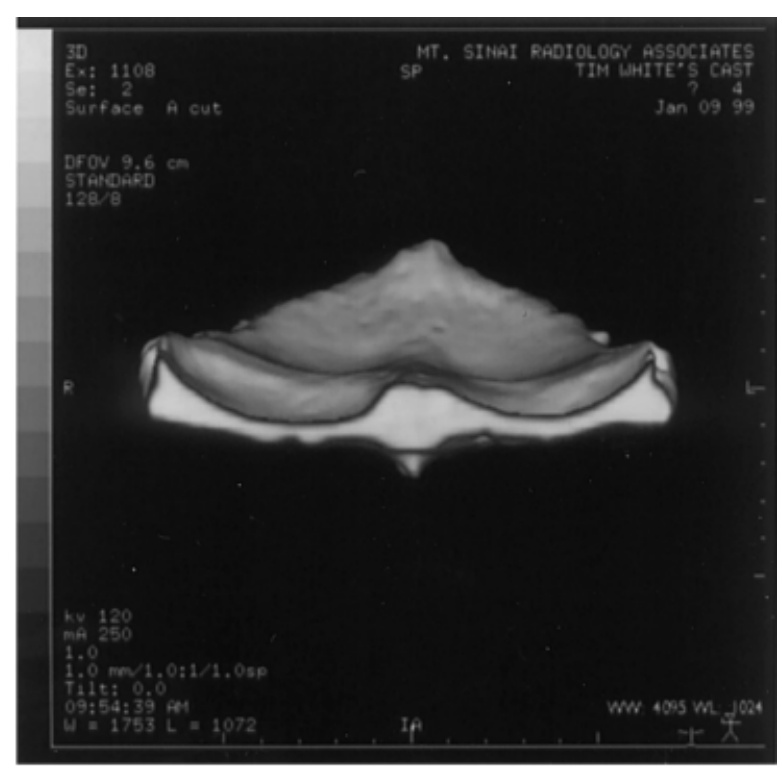

C

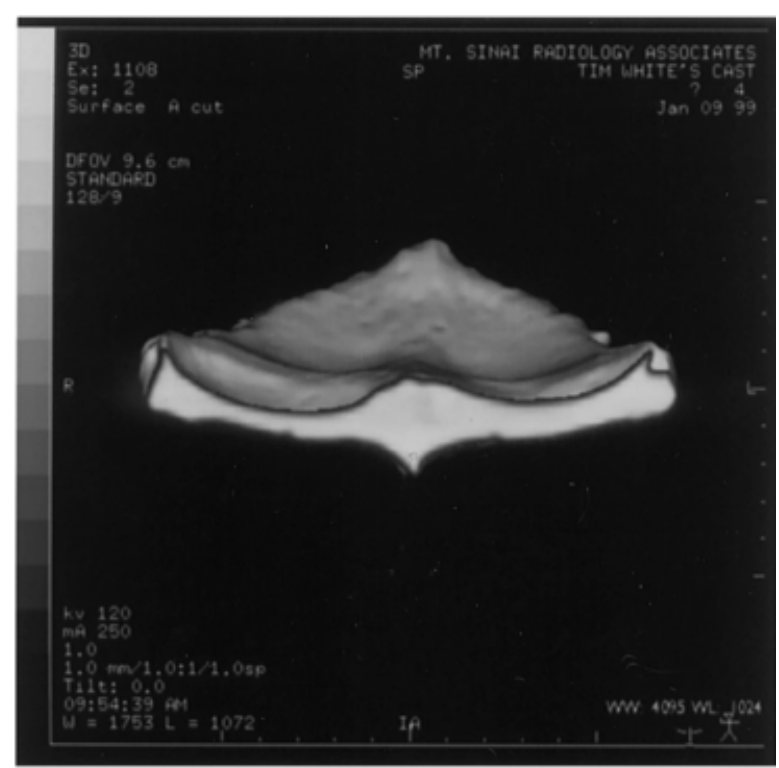

D

Fig. 6. A: Computer tomographic sections through a cast of the Omo L338y-6 occipital bone. B-D: Sections of the disputed region. The right side of the figure is the left side of the occipital portion. Neither of these sections shows any evidence of an elevation or depression that could be interpreted as an enlarged $\mathrm{O} / \mathrm{M}$.

cleaned and recast Omo L338y-6 occipital portion, as claimed by White and Falk (1999).

2. Both OH5 and SK 1585 brain endocasts show strong morphological evidence for $\mathrm{O} / \mathrm{M}$ using the same exact methods as employed on Omo L338y-6 described above.

3. Examination of the original Omo L338y-6 fossil failed to locate any trace of an enlarged left O/M.

4. The use of several generations' removed casts from the original specimen by White and Falk (1999) most likely explains the differences in observations.

5. There is a good possibility that buildup of materials along the slightly displaced crack line that outlines the lateral margin of White and Falk's (1999) O/M could provide such an artifact that might be confused with a true $\mathrm{O} / \mathrm{M}$.

6. The taxonomic affinity of Omo L338y-6 cannot be assessed using the negative evidence of a lack of the $\mathrm{O} / \mathrm{M}$ to assure its "robust" Australopithecus morphology, and the Omo L338y-6 specimen may represent Australopithecus africanus or Australopithecus aethiopicus, as Holloway suggested (1988), or Australopithecus boisei, as Rak and Howell (1978) originally suggested. 


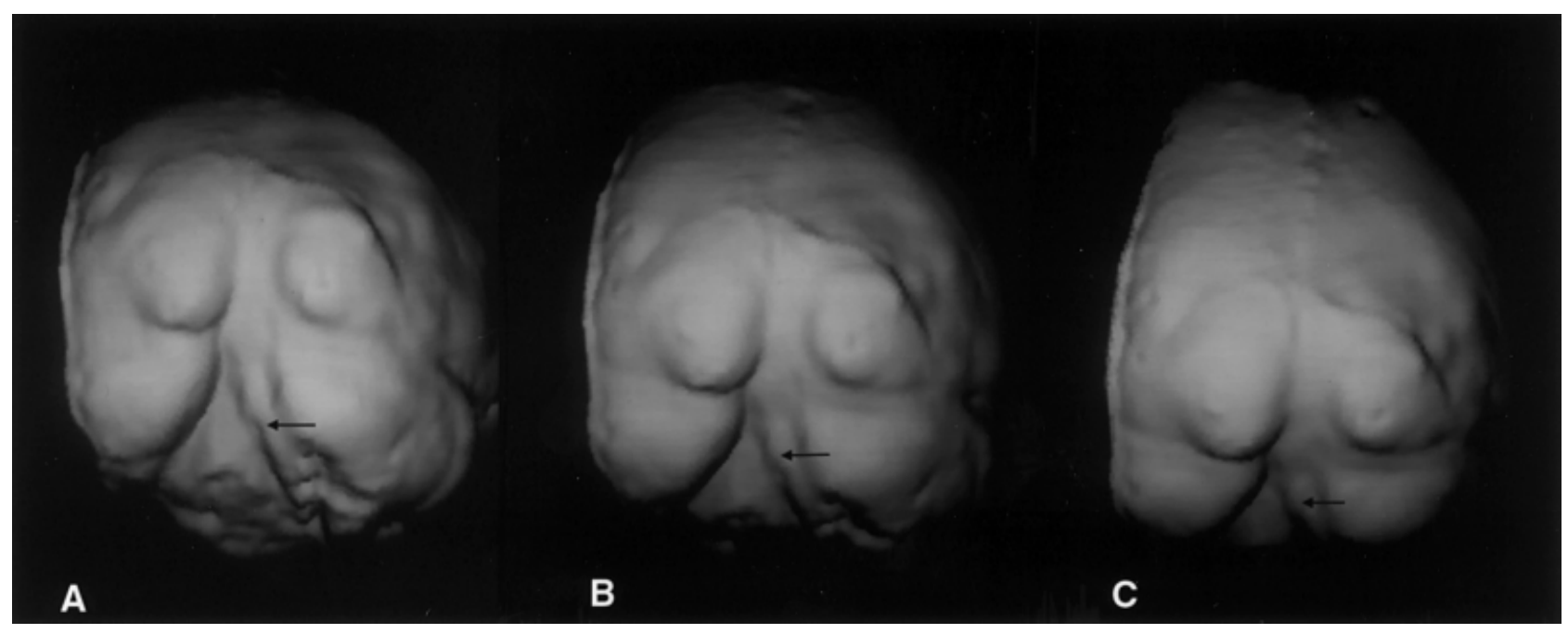

Fig. 7. Computer tomographic 3D reconstruction of the SK 1585 occipital portion of the brain endocast with arrows pointing to the obvious enlarged $\mathrm{O} / \mathrm{M}$ on the right side at various rotating positions $(\mathbf{A}-\mathbf{C})$.

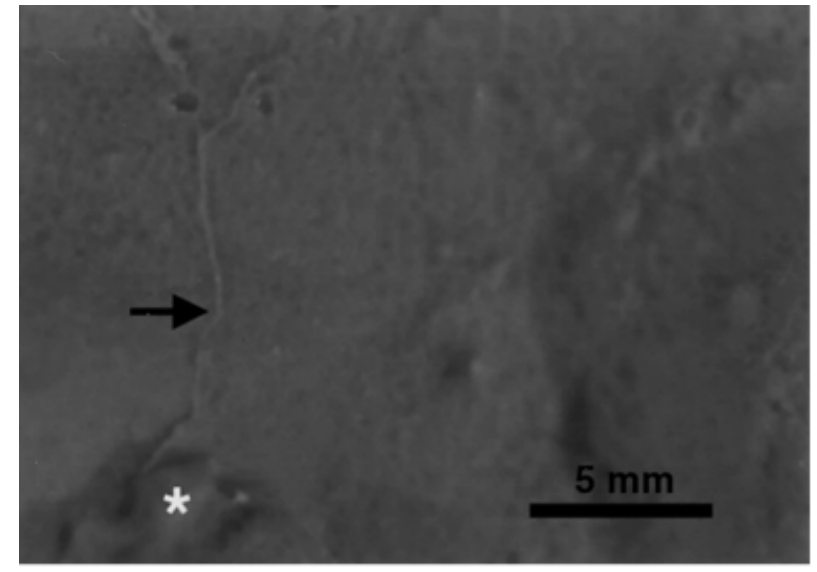

A

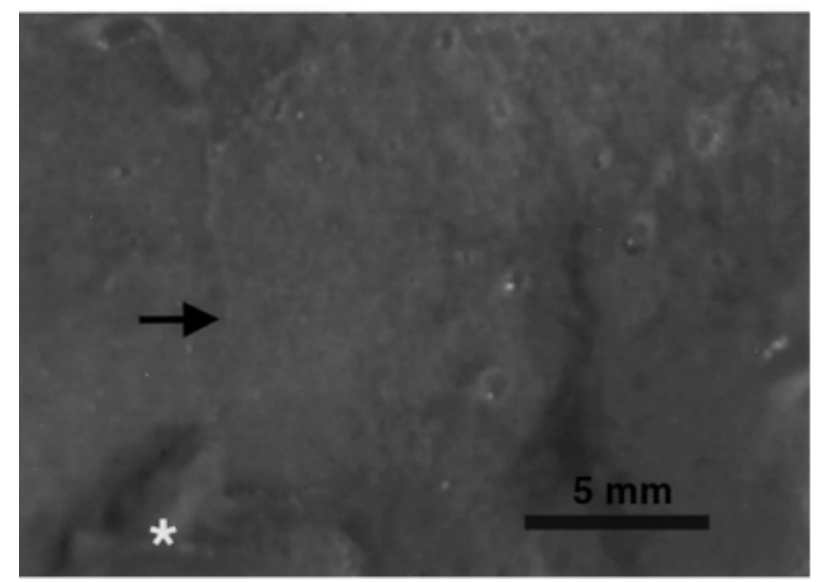

C

Fig. 8. This shows different polyvinylsiloxane and rubber latex peels of the disputed area from different Omo L338y-6 casts of the occipital bone. A: From the first-generation hydrostone cast made by T.D.W. B:

From a cast of the same specimen from the Musée de L'Homme (Paris). C: From a cast from the AMNH. D: From the original AMNH endocast

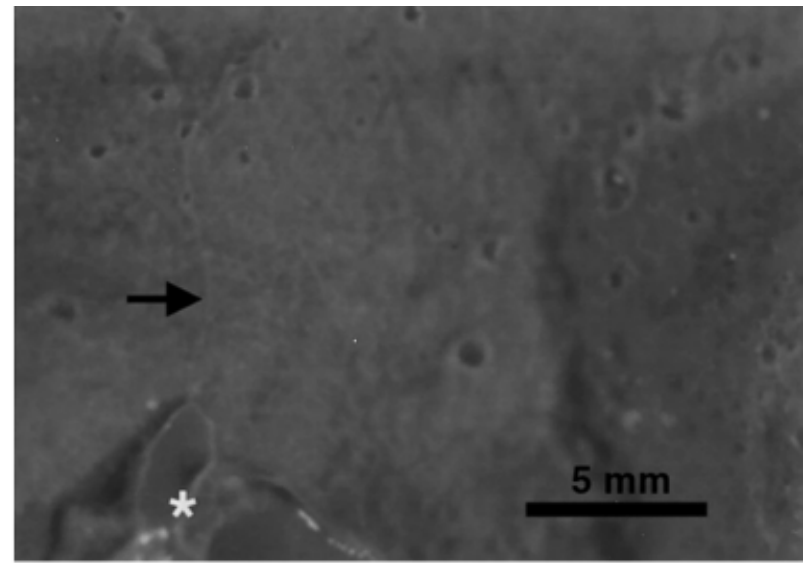

B

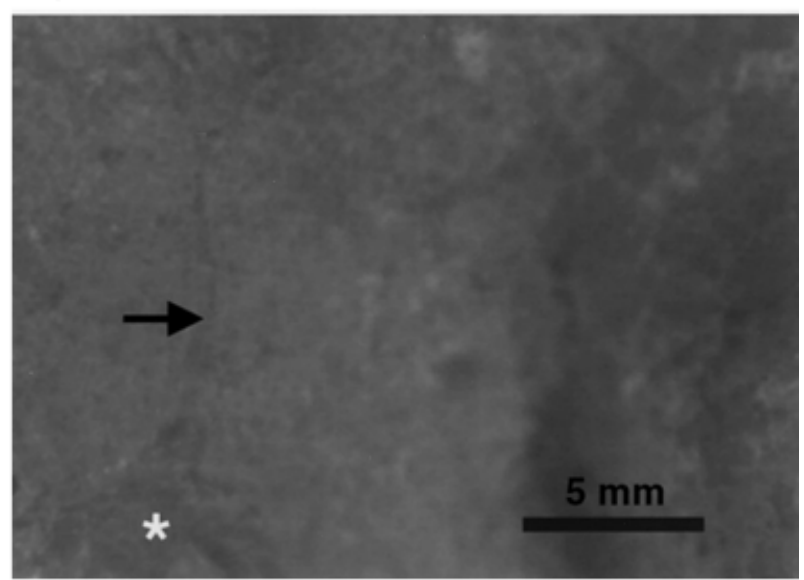

D

reconstructed by R.L.H. Note that in all four peels the crack line does appear (marked by arrows), although it is clearly strongest in the T.D.W. cast. None of the peels provide any evidence of a left enlarged O/M. A-C contain artifact bubbles outside the region of interest from the molding process. 


\section{ACKNOWLEDGMENTS}

We thank Mr. Chet C. Sherwood and Mr. Francys X. Subiaul at the Department of Anthropology, Columbia University, for their help and valuable comments during the preparation of this manuscript. We are similarly grateful to Mr. Sam Márquez and Mr. Ken Mowbray for their help with the casts of these specimens. We also thank Prof. F. Clark Howell and the Omo Expedition for recovering this fossil and making it available for study.

\section{REFERENCES}

Arsuaga JL, Martínez I, Gracia A, Lorenzo C. 1997. The Sima de los Huesos crania (Sierra de Atapuerca, Spain). A comparative study. J Hum Evol 33:219-281.

Broadfield DC, Holloway RL, Mowbray K, Silvers A, Yuan MS, Márquez S. 2001. The endocast of Sambungmacan (Sm3): a new Homo erectus from Indonesia. Anat Rec 262:369-379.

Clarke RJ, Howell FC. 1972. Affinities of the Swartkrans 847 hominid cranium. Am J Phys Anthrop 113:287-292.

Falk D. 1986. Evolution of cranial blood drainage in hominids: enlarged occipital/marginal sinuses and emissary foramina. Am J Phys Anthropol 70:311-324.

Falk D, Conroy GC. 1983. The cranial venous sinus system in Australopithecus afarensis. Nature 306:779-781.
Falk D, Redmond Jr JC, Guyer J, Conroy GC, Recheis W, Weber GW, Seidler H. 2000. Early hominid brain evolution: a new look at old endocasts. J Hum Evol 38:695-717.

Grine F. 1988. The evolutionary history of the "robust" australopithecines. New York: Aldine de Gruyter. 527 p.

Holloway RL. 1981. The endocast of the Omo juvenile L338y-6 hominid specimen. Am J Phys Anthropol 54:109-118.

Holloway RL. 1988. "Robust" australopithecine brain endocasts: some preliminary observations. In: Grine F, editor. The evolutionary history of the "robust" australopithecines. New York: Aldine de Gruyter. p 97-106.

Kimbel WH. 1984. Variation in the pattern of cranial venous sinuses and hominid phylogeny. Am J Phys Anthropol 63:243-263.

O'Loughlin VD. 1996. Comparative endocranial vascular changes due to craniosynostosis and artificial cranial deformation. Am J Phys Anthropol 101:369-385.

Rak Y, Howell FC. 1978. Cranium of a juvenile Australopithecus boisei from the lower Omo Basin, Ethiopia. Am J Phys Anthropol 48:345-366.

Suwa G, Asfaw B, Beyene Y, White TD, Katoh D, Nagaoka S, Nakaya K, Uzawa K, Renne P, Wolde Gabriel G. 1997. The first skull of Australopithecus boisei. Nature 389:489-492.

White DD, Falk D. 1999. A quantitative and qualitative reanalysis of the endocast from the juvenile Paranthropus specimen L338y-6 form Omo, Ethiopia. Am J Phys Anthropol 110:399-406.

White TD. 2000. A view on the science: physical anthropology at the millenium. Am J Phys Anthrop 113:287-292. 